WORLD VIEW

\title{
Traditional healers' roles on eye care services in Nepal
}

\section{A K Poudyal, M Jimba, B K Poudyal, S Wakai}

Series editors: W V Good, S Ruit

Br J Ophthalmol 2005;89:1250-1253. doi: 10.1136/bjo.2004.065060

See end of article for authors' affiliations

.....................

Correspondence to: Masamine Jimba, MD, $\mathrm{PhD}, \mathrm{MPH}$, Department of International Community Health, Graduate School of Medicine, The University of Tokyo, 7-3-1 Hongo, Bunkyo-ku, Tokyo, $113-$ 0033; mijmba@m.u-tokyo. ac.jp

Accepted for publication 1 March 2005

\begin{abstract}
Aim: To evaluate the traditional healer (TH) training programme carried out by Nepal Netra Jyoti Sangh, a non-governmental organisation in Nepal, by measuring the changes in knowledge and practices of trained $\mathrm{TH} s$ in providing primary eye care services.

Methods: 103 trained THs practising in six districts of Nepal were interviewed with a semistructured questionnaire. Their knowledge about various illnesses and eye care practices were compared before and after the training.

Results: A significant change in the number of $\mathrm{TH} s$ with accurate perceived knowledge about trachoma $(28.2 \%$ v $70.9 \%, p<0.0001)$ and cataract $(54.4 \% \vee 94.2 \%, p<0.0001)$ was found after the training. In total, $98(95 \%)$ THs stopped using traditional eye medicines after receiving the training $(p<0.0001)$. The referral practices of $\mathrm{TH}$ s improved significantly after the training $(15 \% \mathrm{v} 100 \%, \mathrm{p}<0.0001)$. After the training, $95 \%$ of the $\mathrm{TH}$ s used an eye care kit to treat patients with red eyes and simple ocular trauma. Conclusion: The findings show that a $\mathrm{TH}$ training programme on primary eye care services convinced traditional healers to stop the use of traditional eye medicines and improve referral practices in Nepal.
\end{abstract}

$\mathrm{T}$ he World Health Organization (WHO) estimates that approximately 45 million people in the world are blind. Ninety per cent of the blind live in developing countries, and $80 \%$ of global blindness is avoidable. ${ }^{1}$ The 1981 Nepal Blindness Survey showed that $0.84 \%$ of the Nepalese population was bilaterally blind and $1.66 \%$ unilaterally blind. ${ }^{2}$ No national blindness survey has been done since this time. The major causes of blindness in Nepal include cataracts, trachoma, corneal trauma, ulceration, glaucoma, and vitamin A deficiency. ${ }^{2-4}$

To improve eye care, Nepal has increased the number of eye care professionals trained in western medicine. Nepal has only one ophthalmologist per 250000 people, but has approximately 300 ophthalmic assistants and other eye care workers such as optometrists and eye workers. ${ }^{5}$ These ophthalmic assistants serve as the heads of primary eye care centres (PECCs). ${ }^{5}$ PECCs are permanent eye care service centres in the districts. By the end of 2003, 32 PECCs and 11 eye hospitals were providing eye care services in 40 of 75 districts of Nepal (NNJS unpublished report, 2004).

Health service utilisation in Nepal is very poor. The National Planning Commission (HMG/N 1998) showed that only $12 \%$ of household used government health services and more than $25 \%$ of households used non-government health services. ${ }^{6}$ Several studies have shown that traditional healers (THs) are the first people that the Nepalese contact when seeking treatment for health problems, including eye problems. ${ }^{3-8}$

For the prevention of blindness, Nepal has launched a global initiative-Vision 2020: the right to sight-in which human resource development is one of its three major goals. ${ }^{9}$ Research conducted in Zimbabwe and Malawi suggests that a sustainable collaborative programme between traditional and western practitioners could help to reduce preventable blindness by advising against the use of harmful traditional practices..$^{10-13}$

To improve such collaborations, some THs in Nepal have been trained in western medicine. The trained THs showed improved knowledge of western medicine, and were more likely to refer patients to modern health institutions. ${ }^{14-17}$ However, there is no documentation of the roles of trained THs in eye care services in Nepal.
In this study, we sought to evaluate the $\mathrm{TH}$ training programme carried out by a non-governmental organisation (NGO) by measuring the changes of their knowledge and practices in providing primary eye care services.

\section{MATERIALS AND METHODS}

\section{Background}

Nepal Netra Jyoti Sangh (NNJS), an NGO, was established in 1978 to improve eye care services in Nepal. NNJS started the TH training programme in 1994 for several reasons. Firstly, most of the patients who visited eye hospitals or eye care centres had first consulted local THs. Secondly, more patients visited eye hospitals and eye care centres in the very late stages of their eye problems. Thirdly, communication between THs and modern eye healthcare providers was poor.

NNJS obtained this information from the hospital records of the Nepal Eye Hospital in Kathmandu and a survey report conducted by the NNJS at 15 PECCs of Nepal in 1993 (NNJS unpublished report, 1994).

Considering these factors, NNJS started the TH training programme for modern eye care services in Nepal (NNJS, unpublished report, 1994).

NNJS selected THs who were highly respected and renowned in their communities from those districts where permanent eye care service centres were available. On average, NNJS trained 25 THs from each district. From 1994 to 2003, NNJS trained 422 THs in 18 rural districts of Nepal.

The training had three objectives. The first was to give basic knowledge about eye related illnesses to the THs. The second was to encourage them to refer eye patients to PECCs and eye hospitals without delay. The third was to advise the THs not to use any traditional eye medicines.

NNJS provided the THs with a 3 day long training on primary eye care services. Then, once a year, NNJS provided 1 day refresher training to all the previously trained THs.

On the last day of both the initial and refresher training, an eye care kit was distributed to all the participants free of charge. The kit contained a bottle of chloramphenicol eye

Abbreviations: NGO, non-governmental organisation; PECCs, primary eye care centres; $\mathrm{TH}$, traditional healer 
ointment (the bottle contained 100 small tubes of $1 \%$ chloramphenicol eye ointment), eye health education posters, recording and reporting forms, and referral slips.

\section{Data collection and analysis}

Of 18 districts, we selected six districts; Kavrepalanchowk, Shindhupalchowk, Dhading, Chitwan, Palpa, and Gulmi for this study. These districts were chosen as other districts had security risks caused by the current Maoist insurgency.

Before the training, NNJS had interviewed all the THs to collect baseline information. Based on the pretraining interview questionnaire and the training curriculum on primary eye care services, we developed a semistructured interview questionnaire to evaluate the training programme. The questionnaire included questions about the causes of illness, knowledge of preventive measures, signs and symptoms of eye illnesses, methods of treatment, and referral practices.

We asked THs about various illnesses and categorised their "claimed knowledge" about any specific illness as the "perceived knowledge." Then, we examined their claimed knowledge by comparing their responses with the "standardised knowledge" taken from the $\mathrm{TH}$ training manual developed by NNJS (NNJS, unpublished TH training manual, 1994).

The targets of this study were 162 trained THs of six districts; of these 162, we interviewed 103. Fifty nine THs could not come to the interview because of the unstable political situation.

Before the interview, we informed each TH that we would maintain their confidentiality and anonymity. We also told them that their participation was voluntary, and that if they wished to withdraw from the study, they could leave at any point without any obligation. We then obtained their consent for their participation in the study. Nepal Health Research Council, Nepal approved this study and gave ethical permission.

Four experienced and trained research assistants interviewed each $\mathrm{TH}$ for about 45 minutes. We completed the entire interview in April 2004.

All the data were coded and entered into a Microsoft Visual FoxPro 5.0 database. The data were then analysed with SPSS 11.0 for Windows 2000. We used McNemar test and $\chi^{2}$ test to compare the knowledge and eye care practices of THs before and after the training.

\section{RESULTS}

Of the 103 THs, two (2\%) were female. The mean age of all the respondents was 57.8 years (SD 11.4). Their mean duration of practising traditional healing was 32.4 years
(SD 14.3); 65\% of them were literate. The median year of training after the initial training was 5 years (range 47 years). Agriculture was the major source of their income. However, $11 \%$ of them were earning their major income from traditional healing. Seventy six per cent of them mentioned that they received payment in kind or cash when they treated their patients.

All the THs were living within 3 hours' walking distance from the nearest health posts or subhealth posts. Among them, $80 \%$ were living within 1 hour walking distance from the nearest health posts or subhealth posts. Forty per cent of them could reach the district PECCs within 1 day on foot or by vehicles from their communities. For $60 \%$ of them, it took about 2 days' walk. Regardless of the TH's number of annual refresher training, we did not find any significant differences in the knowledge about eye care among the trained THs.

Table l summarises the THs' perceived knowledge about various illnesses before and after the training. The THs with younger age groups ( $31-40,41-50$, and 51-60 years) showed changes in the perceived knowledge in all the illnesses compared to the age group above 61 years. After the training, 15 THs did not know about night blindness; among them nine $(60 \%)$ were in the above 60 age group. Similarly, 17 $(57 \%)$ in the above 60 age group did not know about trachoma.

Regarding treatment by the THs, $95 \%$ of the THs stated that they treated patients who complained of red eye and simple ocular trauma with the chloramphenicol eye ointment tubes after the training. As taught in the training, they treated each patient with three tubes of eye ointment. However, 79\% of the THs stated that they had used up their medicines at the time of our data collection. Of 103 THs, 95\% wanted to have more eye ointment tubes.

We also saw striking changes in the THs' referral practices. Before the training, 15\% of the THs stated that they referred their patients with general health problems to health posts/ subhealth posts or hospitals when they could not diagnose or treat them. After the training, all the THs referred patients with general health problems to health posts/subhealth posts $(p<0.0001)$. They referred eye patients directly to district PECCs or eye hospitals. The THs reported that, on average, 60 eye patients visited them last year. According to the reports of the THs, a TH referred 18 eye patients, on average, to the district PECCs or hospitals last year. Three per cent of the THs reported that they used referral slips to refer the patients. Most of the trained traditional healers verbally referred eye patients to the district PECCs or hospitals. Of the total, $73 \%$ of the THs said that they submitted the records of referred patients to the training instructors at the refresher training.

Table 1 Traditional healers' (THs) perceived knowledge about various illnesses

\begin{tabular}{llll}
\hline THs & Before training & After training & p Value \\
\hline Illness & $\mathrm{n}=103(\%)$ & $\mathrm{n}=103(\%)$ & \\
Communicable diseases & $60(58.3)$ & $85(82.5)$ & $<0.001$ \\
$\quad$ Know & $18(17.5)$ & \\
$\quad$ Do not know & $43(41.7)$ & $87(84.5)$ & $<0.0001$ \\
Malnutrition & $53(51.5)$ & $16(15.5)$ & \\
$\quad$ Know & $50(48.5)$ & $88(85.4)$ & $<0.001$ \\
$\quad$ Do not know & $67(65.0)$ & $15(14.6)$ & \\
Night blindness & $36(35.0)$ & $97(94.2)$ & $<0.0001$ \\
$\quad$ Know & $56(54.4)$ & $6(5.8)$ & \\
$\quad$ Do not know & $47(45.6)$ & $73(70.9)$ & $<0.0001$ \\
Cataract & $29(28.2)$ & $30(29.1)$ & \\
$\quad$ Know & $74(71.8)$ & Do not know & \\
Trachoma & Know & & \\
Do not know & & & \\
\hline
\end{tabular}

We asked further questions to only those THs who claimed that they knew about various illnesses. 
Table 2 Knowledge of traditional healers (THs) about signs and symptoms of cataract and trachoma

\begin{tabular}{llll}
\hline THs & Before training & After training & p Value \\
\hline Cataract & $\mathrm{N}=56(\%)$ & $\mathrm{n}=97(\%)$ & \\
Correct & $46(82.1)$ & $95(97.9)$ & $<0.001$ \\
Incorrect & $10(7.9)$ & $2(2.1)$ & \\
Trachoma & $\mathrm{N}=29(\%)$ & $\mathrm{n}=73(\%)$ & $<0.0001$ \\
Correct & $18(62.1)$ & $68(93.2)$ & \\
Incorrect & $11(37.9)$ & $5(6.8)$ & \\
\hline
\end{tabular}

Of six district PECCs, the ophthalmic assistants of three district PECCs told us that they received referral patients from THs, but the number of referral slips was small. They also mentioned that some patients visited the PECCs on the THs' recommendation. An ophthalmic assistant in Chitwan district PECC said that a trained TH referred 45 patients with mature cataract in 1 year and all of them were operated. However, all six PECCs had no record keeping system for the referred patients and THs. The last 5 years' medical records in the district PECCs and Nepal Eye Hospital showed that the number of patients with corneal ulcers was gradually declining compared to 5 years ago.

For the use of traditional treatment methods, before the training, $72 \%$ of the THs applied traditional eye medicines in their patients' eyes, whereas only $5 \%$ of them continued to use traditional eye medicines after the training $(p<0.0001)$. Before the training, the THs used extracts of the roots, leaves of trees, seeds; herbs; powdered glass; breast milk and human urine; excreta from dog and birds as traditional eye medicines.

\section{DISCUSSIONS}

This study showed that the TH training on primary eye care services was successful in achieving three training objectives. Firstly, the training improved the $\mathrm{THs}^{\prime}$ knowledge about common illnesses and eye related problems. Secondly, most THs stopped using traditional eye medicines. Thirdly, they referred the eye patients to the district PECCs or eye hospitals.

The study also revealed that the THs in the younger age groups (31-40, 4l-50, and 51-60 years) acquired more standardised knowledge about eye care than the above 60 year age group. This finding suggests that the future training should target younger THs below 60 years old.

We found a gap between perceived knowledge and standardised knowledge in this study. As tables 2, 3, and 4 showed, their perceived knowledge about various illnesses did not match the standardised knowledge before the training.

Table 2 shows that the THs' knowledge on cataract and trachoma increased after the training. In both cataract and trachoma, all the incorrect knowledge was found among the above 60 years age group.

Table 3 shows that the training significantly improved the THs' knowledge about the preventive measures for malnutrition, night blindness, and trachoma. Among 22 THs who still had incorrect knowledge about preventive measures of night blindness, nine $(41 \%)$ were from the above 60 age group.

Table 4 shows a significant difference between two groups in their knowledge about the treatment of cataract and trachoma.

Two main reasons may explain the gap between the perceived knowledge and standardised knowledge. Firstly, we assume they wanted to show us that they were knowledgeable healers and to maintain their reputation. In her anthropological study in Nepal, Pigg mentioned that THs do not want to lose their prestige by showing little knowledge. ${ }^{18}$ Secondly, they were afraid of losing chances of attending the training course by answering negative responses.

Besides improving the standardised knowledge, the THs also improved their practices after the training. Before the training, $60 \%$ of the THs were using traditionally used plants along with other substances for treating eye problems. Some of the traditional eye medicines are known to be contaminated, and they may provide a vehicle for the spread of pathogenic organisms. ${ }^{19}{ }^{20}$ Therefore, NNJS advised the THs not to use traditional eye medicines, and $95 \%$ of the THs stopped using them after the training.

In this study, $79 \%$ of the THs mentioned that they had used up chloramphenicol; and $90 \%$ of THs asked for more. To refill the eye care kit, the THs had to wait up to 1 year till the next refresher training course. There was no system of supplying eye medicines to the THs who used them up within a year. If sufficient eye ointments are provided to the THs free of charge, the THs will not suffer from the lack of medicines. Therefore, NNJS and the THs should develop an appropriate system to refill the eye care kit.

As NNJS expected, most of the THs referred eye patients to the district PECCs or hospitals when they could not treat them. The THs knew that many health posts/subhealth posts were unable to provide eye care. Therefore, they directly referred eye patients to district PECCs and hospitals. Since 2000, however, eye care has been integrated with the general

Table 3 Traditional healers' (THs) knowledge of preventive measures for various illnesses

\begin{tabular}{llll}
\hline THs & Before training & After training & p Value \\
\hline Malnutrition & $\mathrm{n}=53(\%)$ & $\mathrm{n}=87(\%)$ & \\
Correct & $46(86.8)$ & $85(97.7)$ & $<0.001$ \\
Incorrect & $7(13.2)$ & $2(2.3)$ & \\
Night blindness & $\mathrm{n}=67(\%)$ & $\mathrm{n}=88(\%)$ & $<0.001$ \\
Correct & $7(10.4)$ & $66(75.0)$ & \\
Incorrect & $60(89.6)$ & $22(25.0)$ & \\
Trachoma & $\mathrm{n}=29(\%)$ & $\mathrm{n}=73(\%)$ & $<0.0001$ \\
Correct & $18(62.1)$ & $68(93.2)$ & \\
Incorrect & $11(37.9)$ & $5(6.8)$ & \\
\hline
\end{tabular}


Table 4 Traditional healers' (THs) knowledge about where to refer patients with cataract and trachoma for treatment

\begin{tabular}{llll}
\hline THs & Before training & After training & p Value \\
\hline Cataract & $\mathrm{n}=56(\%)$ & $\mathrm{n}=97(\%)$ & \\
Correct & $31(55.4)$ & $92(94.8)$ & $<0.0001$ \\
Incorrect & $25(44.6)$ & $5(5.2)$ & \\
Trachoma & $\mathrm{n}=29(\%)$ & $\mathrm{n}=73(\%)$ & $<0.0001$ \\
Correct & $19(65.5)$ & $71(97.3)$ & \\
Incorrect & $10(34.5)$ & $2(2.7)$ & \\
\hline
\end{tabular}

healthcare system in Nepal. NNJS has thus started primary eye care training to some of the health posts in charges of their target district. The THs have also started to be advised to refer their patients to the health posts. This practice is still new, but eye patients will be referred to the PECCs or eye hospitals through the health posts in future.

Though NNJS started the TH training 10 years ago, a systematic referral system has not yet been developed. Therefore, the referred patients were also not registered according to the respective trained $\mathrm{TH}$ of each district. However, the last 5 years' medical records in the district PECCs and Nepal Eye Hospital showed that the number of patients with corneal ulcers was gradually declining. This might be because the THs stopped using traditional eye medicines.

NNJS provided the training only to those THs who met the selection criteria. Therefore, their average literacy rate was higher compared with the national average. Such selection indeed may create a bias and the result may not be applicable to all THs in Nepal. However, this selection is practical and meaningful as we can apply such selection methods in rural Nepal as long as THs remain as major health providers.

In conclusion, the THs' training programme on primary eye care services was successful in convincing the THs to stop using traditional eye medicines and improve referral practices in Nepal. However, how to establish a sustainable medicine supply system remains a challenge for future.

\section{ACKNOWLEDGEMENTS}

We acknowledge Dr Ram Prasad Pokhrel, the chairperson of Nepal Netra Jyoti Sangh (NNJS) for allowing us to conduct this study on their traditional healer training programme on primary eye care. We thank NNJS and staff members who helped us to conduct the fieldwork. We thank the district primary eye care centres' staff members and the traditional healers for participating in this study. The views expressed in this paper are entirely those of the authors and do not necessarily reflect the views of the organisations they serve.

\section{Authors' affiliations}

A K Poudyal, M Jimba, S Wakai, Department of International Community Health, Graduate School of Medicine, The University of Tokyo, Japan

A K Poudyal, Department of Community Medicine and Family Health, Institute of Medicine, Tribhuvan University, Kathmandu, Nepal
B K Poudyal, Nepal Netra Jyoti Sangh, Eye Health Education Unit, Kathmandu, Nepal

\section{REFERENCES}

1 World Health Organization. Blindness: vision 2020. The global initiative for the elimination of blindness, www.who.int/mediacentre/factsheets/fs213/ en/ 2000 (accessed on 19 June 2004).

2 Brilliant G. The epidemiology of blindness in Nepal: report of the $1981 \mathrm{Nepal}$ blindness survey. Chelsea, MI: Seva Foundation, 1988.

3 Upadhyaya MP, Karmacharya PCD, Koirala S, et al. Epidemiologic characteristics, predisposing factors and etiologic diagnosis of corneal ulceration in Nepal. Am J Ophthalmol 1991;111:92-9.

4 Khatry SK, Lewis AE, Schein OD, et al. The epidemiology of ocular trauma in rural Nepal. Br J Ophthalmol 2004;88:456-60.

5 Nepal Netra Jyoti Sangh. Eye centres and eye hospitals: a profile of Nepal Netra Jyoti Sangh. Kathmandu, Nepal: National Society for Comprehensive Eye Care, 2000.

6 HMG/N National Planning Commission. Service delivery survey: health and agriculture services. Nepal Multiple Indicator Surveillance Sixth Cycle 1998.

7 Jimba M, Poudyal AK, Wakai S. The need for linking healthcare-seeking behaviour and health policy in rural Nepal. Southeast Asian J Trop Med Public Health 2003;34:2-3.

8 Mesko N, Osrin D, Tamang S, et al. Care for perinatal illness in rural Nepal: a descriptive study with cross-sectional and qualitative components. BMC Int Health Hum Rights 2003;3:3.

9 World Health Organization. Vision 2020: the right to sight, www.v2020.org/ right_to_sight/index.asp (accessed on 22 February 2005).

10 Lewallen S, Courtright P. Role for traditional healers in eye care. Lancet 1995;345:456.

11 Courtright $\mathbf{P}$, Lewallen $S$, Kanjaloti $S$. Changing patterns of corneal disease and associated vision loss at a rural African hospital following a training programme for traditional healers. Br J Ophthalmol 1996;80:694-7.

12 Chana HS, Schwab L, Foster A. With an eye to good practice: traditional healers in rural communities. World Health Forum 1994;15:144-6.

13 Courtright $\mathbf{P}$. Eye care knowledge and practices among Malawian traditional healers and the development of collaborative blindness prevention programmes. Soc Sci Med 1995:41:1569-75.

14 Oswald IH. Are traditional healers the solution to the failures of primary health care in Rural Nepal? Soc Sci Med 1983;17:255-7.

15 Dhakal R, Graham-Jones S, Lockett G. Traditional healers and primary health care in Nepal. Kathmandu: Save the Children Fund-United Kingdom, 1986.

16 Gillam S. The traditional healer as village health worker. J Inst Med 1989;11:67-76.

17 Poudyal AK, Jimba M, Murakami I, et al. A traditional healers' training model in rural Nepal: strengthening their roles in community health. Trop Med Int Health 2003;8:956-60.

18 Pigg SL. Acronyms and effacement: traditional medical practitioners (TMP) in international health development. Soc Sci Med 1995;41:47-68.

19 Yorston D, Foster A. Traditional eye medicines and corneal ulceration in Tanzania. J Trop Med Hyg 1994;97:211-14.

20 Whitcher JP, Srinivasan M, Upadhaya M. Corneal blindness: a global perspective. Bull World Health Organ 2001;79:214-21. 